\title{
Cat Dander Antigen IgG4 Antibody Measurement
}

National Cancer Institute

\section{Source}

National Cancer Institute. Cat Dander Antigen Ig G4 Antibody Measurement. NCI

Thesaurus. Code C130127.

A measurement of the cat dander antigen IgG4 antibody in a biological specimen. 